\title{
LAS PRIMERAS ELECCIONES AL PARLAMENTO BALEAR
}

\section{SUMARIO}

1. Introducción-2. Candidaturas y Campaña electoral.-3. Los Resultados: 3.1: Mallorca; 3.2. Menorca; 3.3. Ibiza; 3.4. Formentera.-4. PARTICIPACIÓN ELECTORAL Y ABSTENCIÓN.

\section{INTRODUCCION}

La Ley Orgánica 2/1983, de 25 de febrero (BOE de 1 marzo 1983), puso punto final al polémico y muy dilatado proceso de elaboración de la «norma institucional básica» de la Comunidad Autónoma de las Islas Baleares. Aunque el referido Estatuto de Autonomía (art. 20) dejaba a una futura ley del Parlamento balear ${ }^{1}$ la regulación de los aspectos electorales básicos (determinación del número totảl de diputados que van a integtarlo, fijación de los distritos electorales y número de diputados que corresponderá elegir a cada uno de ellos), la disposición transitoria segunda-b) estableció unas normas provisionales a aplicar en la primera elección de. la Cámara legislativa regional. Esta regulación transitoria se concretaba en: primero, el número total de diputados a elegir se cifraba en 54: Segundo, se dividía la provincia en cuatro distritos electorales, correspondientes a las cuatro islas habitadas del archipiélago: la isla de Mallorca elegía 30 diputados; la de Menorca, 12; la de Ibiza, 11, y la de Formentera, uno.

De acuerdo con el contenido de esta disposición transitoria, el 8 de mayo de 1983 se celebraron las primeras elecciones al Parlament de les Illes Balears.

\section{CANDIDATURA Y CAMPAÑa ELECTORAL}

Aunque al comienzo de la campaña electoral el tono de enfrentamiento entre las principales formaciones políticas era bastante moderado, el progrèsivo transcurrir

1 A tenor de lo establecido en el párrafo tercero del artículo 20 del Estatuto de Autonomía, dicha ley deberá ser aprobada por la mayoría absoluta de los diputados que integren el Parlamento. 
de la misma fue caldeando los ánimos, de tal manera que, en su recta final, los agrios ataques verbales entre la Unió Mallorquina y Alianza Popular, por una parte, y el Partido Socialista y Alianza Popular, por otra, fueron «animando» una campaña electoral que se había significado por su carácter tedioso, reiterativo y - salvo en el caso del Partit Socialista de Mallorca - carente de originalidad. La escasa participación popular en los actos electorales que de forma casi ritual se fueron programando por los distintos partidos, puso de manifiesto la creencia en amplios sectores de la sociedad balear de que la fecha electoral «importante» había sido el 28 de octubre de 1982, y que estas elecciones autonómicas, de significado mal entendido por mal explicado ${ }^{2}$, tenían menor trascendencia.

La coalición conservadora, integrada por Alianza Popular, Partido Demócrata Popular y Unión Liberal, partió de una realidad sociológica bastante indiscutible: el marcado carácter conservador del electorado isleño ${ }^{3}$. Frases como «Mallorca nunca ha sido socialista. Nunca. No es el socialismo quien nos ha engrandecido, sino la libre empresa», podían leerse con reiteración en la muy cuidada propaganda electoral de la coalición de derechas. Una vez fijado el gran enemigo a batir, el socialismo, tampoco regatearon esfuerzos, ni palabras, para descalificar a la Unió Mallorquina, partido de centro-derecha que, bajo un genérico barniz regionalista, amenazaba con sustraerles - como así ocurrió- parte de su potencial electorado. «Piense que el voto que no sea socialista no puede dispersarse. El día 8 , más que nunca, hay que votar útil. Hay que votar a partidos serios, implantados en todo el Estado», decían los folletos de la derecha, refiriéndose indubitadamente a la Unió Mallorquina, a la que parecían descalificar (partido no serio) por el hecho de no estar implantada en todo el territorio del Estado. El lema de la coalición AP-PDPUL era: «Cañellas Fons con todos y marcha tu autonomía».

El Partido Socialista Obrero Español realizó una coherente campaña electoral que, no obstante algunas deficiencias formales, consiguió concienciar a amplios sectores de la población progresista de las Islas. «Pel Poble» $\mathrm{y}$ «Per un bon govern a les teves Illes» fueron sus eslóganes más repetidos durante toda la campaña, la cual se «montó», básicamente, en torno al político más prestigioso de Baleares, Félix Pons Irazazabal.

La Unió Mallorquina ${ }^{4}$ había nacido a la vida política unos pocos meses antes de esta contienda electoral, y, bajo el liderazgo del antiguo dirigente de UCD, Jerónimo Albertí Picornell, agrupaba a ex militantes de UCD, independientes y algún que otro ex dirigente de Alianza Popular. Se trata de un partido de centro-derecha que aspira a formar parte de la «gran operación reformista» que quiere coordinar el catalán Miguel Roca. Proclaman como valor fundamental de su actuación política «el regionalismo», aunque en la concreción del significado de este valor se pueden constatar ciertas ambigüedades. El lema central de su muy intensa campaña electoral fue «anam per feina» (vamos porque hay trabajo que hacer).

Los nacionalistas de izquierda, agrupados en torno al Partit Socialista de Mallorca - coaligado con el Partit Socialista de Menorca-, hicieron una sugestiva campaña electoral, pese a su notoria escasez de recursos económicos, sólo mitigada a tra-

2 A nuestro entender, algunas formaciones políticas desenfocaron, muy conscientemente, el significado real de esta consulta.

${ }_{3}$ Un análisis de la evolución del voto balear durante el segundo período republicano (1931-1936) y de las posibles líneas de continuidad electoral entre aquella etapa y la actual experiencia democrática (1977-1982) puede consultarse en mi libro La Segunda República en Baleares: partidos políticos y elecciones, Palma de Mallorca, Institut d'Estudis Baleàrics, 1983.

${ }^{4}$ En la candidatura de la Unió Mallorquina -circunscrita sólo a la isla de Mallorcafiguraban algunos nombres del Partido Demócrata Liberal. Por el contrario, en Ibiza y Formentera, el PDL presentó - como veremos - candidatura propia. 
vés de la inteligente movilización de sus militantes. Su lema electoral «ara més que mai» (ahora más que nunca), ponía de relieve la importancia de estos comicios para el redescubrimiento de la identidad propia del pueblo de las Islas.

Las otras candidaturas que concurrieron a las elecciones del Parlamento balear fueron las siguientes: el Centro Democrático y Social, el Partido Comunista de España-Partit Comunista de les Illes Balears, el Partido Comunista Obrero Español, el Partido Demócrata Popular (Ibiza y Formentera) y la Candidatura Independent de Menorca.

A pesar de los enfrentamientos verbales referidos al principio, hay que precisar que la jornada electoral del 8 de mayo transcurrió en Baleares con absoluta normalidad, sin que se registrasen incidentes dignos de mención de ningún tipo.

\section{LOS RESULTADOS}

Para una mejor comprensión del significado real de los resultados producidos, con los datos que nos ha proporcionado el Gobierno civil de Baleares, hemos elaborado dos cuadros, que se incluyen en la página siguiente.

\subsection{Mallorca}

Aunque en la isla de Mallorca el PSOE mantuvo su condición de fuerza mayoritaria (obtuvo 89.016 votos frente a los 88.335 de la coalición AP-PDP-UL), hay que dejar constancia de que los votos de la derecha sociológica (AP-PDP-UL y Unió Mallorquina) fueron muy superiores a los de la izquierda (PSOE, PSM, PCE-PCIB y PCOE), lo que testimoniaba, una vez más, el marcado componente conservador de esta Isla. Mientras en Palma el Partido Socialista aventajaba en más de 10.000 sufragios a la coalición de derechas, ésta mostraba su mejor arraigo en las zonas rurales (en veintitrés municipios la coalición AP-PDP.UL obtuvo mayoría, mientras que el Partido Socialista sólo la consiguió en once). En los municipios de Mallorca en donde estaban censados numerosos trabajadores de los sectores secundario (industria) y terciario (hostelería), el PSOE obtuvo buenos resultados (verbi gracia, Arta, Llucmajor, Calvià, etc.), mientras que las zonas dedicadas al sector primario (agricultura y ganadería) optaron abrumadoramente por las ofertas conservadoras, bien AP-PDP-UL (v.g., Muro, Montuiri, Sa Pobla, Villafranca de Bonany, etc.), bien Unió Mallorquina (v. g., San Juan, Escorca, Santa Margarita, Porreres...).

La Unió Mallorquina heredó el electorado de UCD y arrebató al CDS parte del que había obtenido en las elecciones generales de 1982; sin embargo, creemos que no consiguió sustraer a AP-PDP-UL votos en cantidad mínimamente significativa ${ }^{5}$. Como ya hemos apuntado, su implantación fue relativamente importante en las zonas rurales (fue la fuerza política más votada en dieciocho municipios) ${ }^{6}$, mientras que en Palma obtuvo un apoyo casi simbólico (de sus 47.390 votos sólo 12.062 fueron escrutados en las mesas electorales de la capital).

5 Los votos que obtuvo la formación del ex president Albertí (47.390) fueron prácticamente los mismos que obtuvo la Unión de Centro Democrático en las elecciones generales de octubre de $1982(37.142)$ y los perdidos en estas consultas por el Centro Democrático y Social (12.071).

${ }^{6} \mathrm{La}$ cifra de dieciocho municipios es algo engañosa, ya que diez de ellos son poblaciones de menos de 1.000 habitantes (Ariany, Bañalbufar, Buger, Costix, Deià, Escorca, Lloret de Vista Alegre, Mancor del Valle, Santa Eugenia y Valldemossa). 
REPARTO DE VOTOS, PORCENTAJES * Y ESCAÑOS EN LOS CUATRO DISTRITOS ELECTORALES

DE LA COMUNIDAD BALEAR

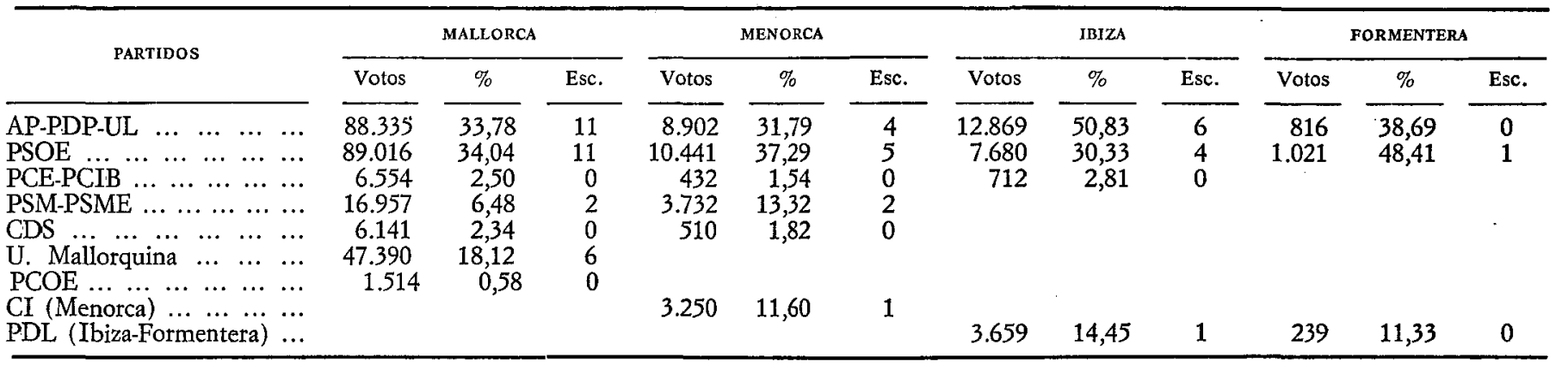

* Los porcentajes están elaborados sobre el total de votos emitidos en cada distrito electoral.

\section{RESUMEN PROVINCIAL}

Censo electoral ......... 489.108

Total votantes $\ldots . . . . . \quad 316.889$

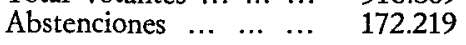

\begin{tabular}{|c|c|c|c|c|}
\hline PARTIDOS & Votos & $\begin{array}{l}\text { Porcentaje } \\
\text { sobre total } \\
\text { votantes }\end{array}$ & $\begin{array}{l}\text { Porcentaje } \\
\text { sobre censo } \\
\text { electoral }\end{array}$ & Escaños \\
\hline PCOE & 1.514 & 0,47 & 0,30 & 0 \\
\hline PCE-PCIB $\ldots \ldots \ldots$ & 7.698 & 2,42 & 1,57 & 0 \\
\hline PSM-PSME $\ldots \ldots \ldots$ & 20.689 & 6,52 & 4,22 & 4 \\
\hline $\begin{array}{lllll} & & \ldots & \ldots\end{array}$ & 108.158 & 34,12 & 22,11 & 21 \\
\hline CI Menorca ... ....... & 3.250 & 1,02 & 0,66 & 1 \\
\hline $\operatorname{CDS} \ldots \ldots \ldots \ldots$ & 6.651 & 2,09 & 1,35 & 0 \\
\hline PDL (Ibiza-Form.). & 3.898 & 1,23 & 0,79 & 1 \\
\hline U. Mallorquina ... ... & 47.390 & 14,95 & 9,68 & 6 \\
\hline AP-PDP-UL $\quad \ldots \quad \ldots$ & 110.922 & 35,00 & 22,67 & 21 \\
\hline
\end{tabular}


Tanto el Partit Socialista de Mallorca (16.957) como el Partido Comunista de España (6.554) recuperaron parte de los votos que habían perdido en las elecciones legislativas del 28 de octubre de 1982. El primero de ellos obtuvo dos diputados por este distrito electoral de Mallorca, y fue la formación política mayoritaria en el municipio de Sineu.

Junto a la práctica desaparición del Centro Democrático y Social, hay que dejar también constancia de la virtual extinción de las fuerzas políticas marginales, de ultraderecha o de ultraizquierda, que habitualmente solían presentarse a los comicios. En esta ocasión sólo presentó candidatura el Partido Comunista Obrero Español, cuyo resultado (1.514 votos) no alcanza siquiera el valor de testimonial. En las demás islas, estas formaciones extremistas desaparecieron radicalmente.

\subsection{Menorca}

Manteniendo viva su tradición política progresista, fue Menorca ${ }^{7}$ la ișla del archipiélago que se mostró más propensa a las opciones de izquierda, especialmente al Partido Socialista Obrero Español, quien, con 10.441 votos, se mantuvo cómodamente como la primera fuerza política del distrito, obteniendo mayoría en los municipios de Mahón, Alayor y Villacarlos. Por contra, la coalición AP-PDP-UL (8.902 votos) la consiguió en Ciudadella, Ferrerías y Mercadal. El Partit Socialista de Menorca obtuvo una nada despreciable cuota electoral (3.732 votos), que le permitió sentar a dos de sus candidatos en el Parlament. La Candidatura Independent de Menorca, agrupación electoral integrada por antiguos militantes de UCD, consiguió 3.250 sufragios favorables, lo que le permitió obtener un acta de diputado; buena parte de sus votos los obtuvo en el municipio de San Luis, en donde fue la candidatura más votada. El CDS (510 votos) y el PCE-PCIB (432 votos), por su escaso respaldo electoral, fueron las dos únicas formaciones menorquinas que no consiguieron representación parlamentaria.

\subsection{Ibiza}

Ibiza, el feudo más fiel a Alianza Popular de todo el Estado español $\mathbf{8}$, manteniéndose en coherencia con su conservadurismo ancestral, dio el triunfo, en los cinco municipios de la Isla, a la coalición conservadora (obtuvo 12.869 votos favorables frente a los 7.680 del PSOE). Mientras en Eivissa-Vila los votos de las dos.

7 Para una aproximación a la realidad política, económica y cultural de la isla de Menorca, pueden consultarse, entre otros, Emili Farre Escofet, La via menorquina del creixement, Barcelona, Servei d'Estudis Banca Catalana, 1977; Deseado Mercadal Bagur, Los Ayuntamientos de Mabón a través de la bistoria, Mahơn, Edició Ajuntament de Maó, 1975; Andreu Murillo, «Els intents autonòmics de- Menorca», en Segones Jornades del CIEMEN, Palma de Mallorca, 1978; J. M. Quintana, Menorca, segle XX, Palma de Mallorca, Moll, 1976; íd., Els menorquins i l'autonomia, Palma de Mallorca, Moll, 1977; Tomás Vidal Bendito, «Evolución de la agricultura y la propiedad en la isla de Menorca», en Revista de Menorca, Mahón, 1968-69.

${ }^{8}$ Es imposible entender la realidad superestructural ibicenca sin tener presente su infraestructura económica, en cuya orientación y dirección juega un papel muy destacado el dirigente nacional de Alianza Popular Abel Matutes Juan.

Para una aproximación al análisis de la importancia que el fenómeno turístico puede. haber tenido en la formación de la que podríamos denominar «conciencia política ibicenca», cfr. Rosa Valles Costa, "Contribución al estudio del turismo en Ibiza y Formentera», en Boletín de la Cámara Oficial de Comercio y Navegación; núms. 676-677, Palma de Mallorca, 1972. 
fuerzas mayoritarias prácticamente se igualaron, en el resto de la Isla el electorado mantuvo una tendencia conservadora muy firme. Hay que dejar también constancia del relativo éxito (sobre todo si se comparan los resultados con los producidos en el resto del Estado) del Partido Demócrata Liberal (3.659 votos), quien, con una campaña de ataque a Alianza Popular, parece haber heredado el electorado de UCD y del CDS 9 . El Partido Comunista (712 votos) mantuvo su tradicional presencia testimonial en una Isla que, sociológicamente, está muy alejada de sus planteamientos.

\subsection{Formentera}

En la pequeña isla de Formentera, con un solo municipio (San Francisco Javier), un censo electoral de 2.876 electores y un solo escaño que cubrir ${ }^{10}$, se ofrecieron al ciudadano tres opciones: la del PSOE (obtuvo 1.021 votos), la de la coalición AP-PDP-UL (816 votos) y la del Partido Demócrata Popular (239 votos). Desde las elecciones de 1979, el Partido Socialista era la fuerza mayoritaria, y en esta consulta :aumentó notablemente las diferencias.

\section{PARTICIPACION ELECTORAL Y ABSTENCION}

Exceptuando la isla de Formentera, en donde la participación electoral se vio incrementada en 1,5 puntos en relación con las elecciones legislativas del 28 de octubre de 1982, debemos señalar el notable aumento de la abstención en las tres islas mayores. Esta menor participación ciudadana a la hora de votar fue especialmente intensa en Palma, en donde se pasó de un 17,3 por 100 de abstención en las generales a un 40,26 por 100 en las autonómicas. Parece bastante indudable que fue el PSOE el principal perjudicado de este elevado porcentaje de abstención, ya que era en la capital de la Provincia donde el Partido Socialista cosechaba tradicionalmente sus mejores resultados.

\begin{tabular}{|c|c|c|c|c|c|}
\hline & $\begin{array}{l}\text { Censo } \\
\text { electoral }\end{array}$ & Votantes & Abstención & $\%$ votantes & $\%$ abstención \\
\hline 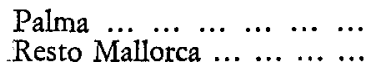 & $\begin{array}{l}212.655 \\
188.172\end{array}$ & $\begin{array}{l}127.026 \\
134.439\end{array}$ & $\begin{array}{l}85.629 \\
53.733\end{array}$ & $\begin{array}{l}59,73 \\
71,44\end{array}$ & $\begin{array}{l}40,26 \\
28,55\end{array}$ \\
\hline Total Mallorca ... ... ... & 400.827 & 261.465 & 139.362 & 65,23 & 34,76 \\
\hline 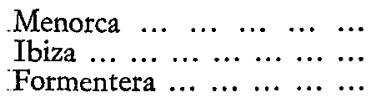 & $\begin{array}{r}42.118 \\
43.267 \\
2.896\end{array}$ & $\begin{array}{r}27.998 \\
25.317 \\
2.109\end{array}$ & $\begin{array}{r}14.120 \\
17.950 \\
787\end{array}$ & $\begin{array}{l}66,47 \\
58,51 \\
72,82\end{array}$ & $\begin{array}{l}33,52 \\
41,48 \\
27,17\end{array}$ \\
\hline Total pRovincia ... ... & 489.108 & 316.889 & 172.219 & 64,78 & 35,21 \\
\hline
\end{tabular}

9 En las elecciones generales de octubre de 1982, el candidato de UCD al Senado por Ibiza-Formentera obtuvo 2.316 votos, y el del CDS 1.089. Parece así confirmarse la existencia en Ibiza de una porción relativamente importante de su cuerpo electoral, que, siendo conservadora, se niega reiteradamente a dar su apoyo a la coalición liderada por Manuel Fraga.

${ }_{10}$ Era la primera vez que la isla de Formentera no formaba circunscripción electoral * conjunta con la de Ibiza. 
En el resto de Mallorca y en la isla de Formentera el índice de participación fue superior al 70 por 100 , mientras que en Menorca la abstención rondó el 33,5 por 100. Ibiza, como en todas las consultas anteriores, fue el distrito que registró un mayor porcentaje de abstención. Alrededor de un 41,5 por 100 de los ibicencos no se acercaron el 8 de mayo a las urnas, cifra que, a tenor de la peculiar idiosincracia política de la Isla, no deja de ser muy significativa y de problemática interpretación.

Joan Oliver Araujo 